\title{
Blending in: A Case Study of Transitional Ambidexterity in the Financial Sector
}

\author{
Beniamino Callegari and Ranvir S. Rai *(D)
}

check for

updates

Citation: Callegari, B.; Rai, R.S. Blending in: A Case Study of Transitional Ambidexterity in the Financial Sector. Sustainability 2021,

13, 1690. https://doi.org/

$10.3390 /$ su13041690

Academic Editor: Andrea Pérez

Received: 31 December 2020

Accepted: 2 February 2021

Published: 4 February 2021

Publisher's Note: MDPI stays neutral with regard to jurisdictional claims in published maps and institutional affiliations.

Copyright: (c) 2021 by the authors. Licensee MDPI, Basel, Switzerland. This article is an open access article distributed under the terms and conditions of the Creative Commons Attribution (CC BY) license (https:// creativecommons.org/licenses/by/ $4.0 /)$.
School of Economics, Innovation, and Technology, Kristiania University College, Oslo 0107, Norway; Ben.Callegari@kristiania.no

* Correspondence: Ranvir.Rai@kristiania.no

\begin{abstract}
Organizational ambidexterity is widely recognized as necessary for the economic sustainability of firms operating in the financial sector. While the management literature has recognized several forms of ambidexterity, the relationship between them and their relative merits remain unclear. By studying a process of implementation of ambidextrous capabilities within a large Scandinavian financial firm, we explore the role of top-down reforms and bottom-up reactions in determining the development of sector-specific innovative capabilities. We find that blended ambidexterity follows naturally from the attempt to correct the tensions arising from harmonic ambidextrous blueprints. The resulting blended practice appears to be closely related to the reciprocal model of ambidexterity, which appears to be a necessity rather than a choice, for large firms attempting to develop innovative capabilities. Consequently, we suggest to re-interpret current taxonomies of ambidexterity not as alternative blueprints, but rather as stages in a long-term process of transition.
\end{abstract}

Keywords: economic sustainability; organizational ambidexterity; blended ambidexterity; innovation process

\section{Introduction}

Organizational ambidexterity has gained considerable attention in management literature since it was first introduced by Robert Duncan in 1976. Originally referring to the ability to use both hands adroitly, the term has been increasingly used in reference to organizations attempting to simultaneously manage both exploitation and exploration to ensure long-term sustainability and competitiveness. Exploitation extends upon current knowledge, seeking greater efficiency and incremental innovation. Exploration, on the other hand, entails the development of new knowledge, experimenting and reaching for more radical innovation [1]. Pursuing and maintaining such opposing business logics and concurrently alleviating related tensions is at the very core of organizational ambidexterity.

The relevance of ambidexterity has been further highlighted by present demands for a transition towards more sustainable business practices. While entirely novel business models can be pioneered by new entrants, spinoffs, and other dedicated experimental market niches, meeting the sustainability challenge also requires incumbents to gradually transform their activities. Such transformation, however, must be conducted while simultaneously maintaining their operations functional and their customers satisfied; while more sustainable options must be explored, exploitation of current opportunities must similarly continue. In other words, from an incumbent perspective, the sustainability transition implies the development and application of ambidexterity.

Extant literature suggests multiple paths to ambidexterity; structural [2], contextual [3] and sequential $[4,5]$ — usually treated as mutually exclusive pathways. However, as recently proposed by Foss and Kirkegaard [6] and as evident from this case study, various modes of ambidexterity may be present at once-ambidexterity can be "blended". Blended ambidexterity may portray a messier yet more realistic picture of "ambidexterity in the 
happening" as companies attempt to lessen some of the negative aspects inherent to any specific ambidexterity mode.

In our study, we focus on the dynamic issues related to the implementation of blended ambidexterity at a large financial organization. More specifically, we examine the issue through a case study of a Norwegian bank - currently undergoing a digital transformation towards becoming a technology-based provider of financial services. In line with previous research [7,8], we investigate how the organization is transitioning between different ambidexterity modes over time in accordance with various challenges and opportunities facing the firm. Our objective is to highlight the unique implementation challenges faced by a top-management team using blended ambidexterity. In particular our theoretical framework leads us to believe that the organization will suffer from significant tensions and paradoxes as they transition from different modes of ambidexterity over time. Our empirical study focuses on exploring the evidence relevant to these transitional changes, and the relative managerial response. We find evidence of a specific transitional trajectory of ambidexterity accompanying the implementation of new practices. The transitional trajectory, and the factors underpinning its course are examined and discussed as part of a transformational strategy for the organization. Additionally, the emergence of specific ambidextrous practices through time have implications for the question of the sustainability of banking business models in the long term.

The article is organized as follows. After this introduction, Section 2 describes our theoretical framework of reference. Section 3 illustrates our methodology. Section 4 contains our findings, which are discussed in Section 5. Finally, Section 6 concludes.

\section{Literature Review}

Smith and Lewis [9] have argued that sustainability is indissolubly linked with the concept of ambidexterity, the ability to balance activities dedicated to exploiting current opportunities and to exploring new methods, business models, and resources, an ability that appears to be vital for the long-term survival of firms [8,10-13]. A successful, sustainable firm is one able to exploit current opportunities and efficiently manage today's demands while also being open to the exploration of new possibilities [13]; to pursue new knowledge while using existing knowledge optimally [12]. In short, a successful firm is more and more commonly described as ambidextrous [4,14-16]. However, not only are there significant differences within the academic community regarding the conceptualization of ambidexterity and its antecedents, there is also substantial heterogeneity in its practical implementation within actual firms.

The various positions can be classified along two main axes. The first regards the understanding of explorative and exploitative activities as either complementary or opposite. The differentiation view argues that explorative and exploitative processes compete for the same resources, their simultaneous implementation involving significant trade-offs $[8,17]$. The integration view argues instead for the presence of significant complementary benefits between the two processes $[3,18,19]$. Consequently, the differentiation view supports implementation strategies based on separate exploration and exploitation activities across business units, while the integration view argues that the processes can, and should, coexist within the same unit. The second axis relates to the temporal dimension of ambidexterity. Exploitation can follow exploration in a more or less rigid alternating sequence [20] or the two activities may always be available for managers and employees to decide when to pursue them $[3,21]$.

Combining these two axes, Simsek et al. [20] propose a classification of ambidexterity in four categories: harmonic, partitional, cyclical, and reciprocal. Harmonic ambidexterity refers to the simultaneous pursuit of exploitation and exploration within a business unit, resulting in processes or systems enabling individual employees and managers to autonomously decide about how to divide their time between conflicting demands [3]. Cyclical ambidexterity, based on the literature on "punctuated equilibrium", refers to the sequential pursuit of exploitation and exploration within a business unit, alternating between 
long periods of exploitation and short bursts of exploration. Partitional ambidexterity refers instead to the simultaneous pursuit of exploitation and exploration across business units, what is commonly referred to in the literature as structural ambidexterity [8]. Finally, reciprocal ambidexterity refers to the sequential pursuit of exploitation and exploration within and across business units.

The latter configuration is certainly the most complex, requiring the establishment of structurally independent units characterized by different, and differently evolving, strategies, structures, and cultures [22]. While each unit operates at least partially independently, they are interdependent with respect to the achievement of ambidexterity. In this reciprocal context, the outputs of exploitation from one unit become the inputs for exploration activities conducted by other units, and vice versa [23]. Such complex configuration implies ongoing information exchange processes, collaborative problem solving activities and resource flows between middle management and the senior management team [24], requiring the presence of a clear shared vision at all operative levels shared vision [25].

While the categorization proposed by Simsek at al. [20] is comprehensive and clear, it is not surprising that empirical realities can be messier. Studying the operation of two business units operating under the William Demant Holding corporate umbrella, Foss and Kirkegaard [6] find evidence of "blending" modes of ambidexterity: the co-presence of structural and contextual ambidexterity, or harmonic and partitional, following Simsek et al. [20] classifications scheme. Specialized organizational units coexist and cooperate with units pursuing both exploitative and explorative activities. Foss and Kirkegaard argue that such configuration is not the result of muddled strategies or faulty implementation processes, but rather the outcome of intentional attempts to mitigate some of the negative aspects inherent to any specific ambidexterity mode, such as the potential loss of specialization advantages under contextual ambidexterity and the problem of diffusing the results of the explorative units activities within exploitative units under structural ambidexterity [14]. The resulting blended approach could also alleviate paradoxical pressures created by the demands of contextual ambidexterity on the individual, through the creation of dedicated supporting units.

An additional issue regarding the classification of ambidexterity regards its evolution over time. The question of how transitions between exploration and exploitation occur in contexts of sequential ambidexterity is still open [19]. Furthermore, due to the limitations linked with any specific approach to ambidexterity, Nosella et al. [7] and O'Reilly and Tushman [8] argue that the most advantageous strategy would involve systematically shifting between ambidexterity modes over time, according to current challenges and opportunities facing the firm. The possibility of blended ambidexterity further muddles the issue, as it is possible that empirical reality could be more correctly described as a shifting mix of ambidexterity regimes, morphing through time. However, the factors dominating the evolutionary shift of the ambidexterity mix through time are yet to be explored.

The link between ambidexterity and sustainability is in evidence within the corporate sustainability discussion that started in management literature in the mid-90s [26], gaining progressively more focus and attention since then [27-29]. In general, corporate sustainability refers to the ability of the firm to both make optimal use of environmental, physical, human, and organizational resources in relation to current knowledge and the existing set of opportunities and constraints as determined by the relevant constellation of stakeholders, while simultaneously cultivating their development over time; a description close to that of the ambidextrous firm [30]. Only through ambidexterity can the sustainable firm guarantee its continued survival by generating value and improving the lives of its stakeholders through time.

In their theoretical review, Sulphey and Alkahtani [31] argue that there is substantial overlapping between corporate ambidexterity and sustainability. The two are argued to complement each other, with sustainability providing the aims and general perspective, and ambidexterity the means and practices. The argument is similar to the one developed by Hahn et al. [32] in regard to the relationship between ambidexterity and corporate social 
performance. Ciasullo et al. [33] provide empirical evidence for structural ambidexterity as a key factor for the realization of sustainability among Chinese multinational firms. Similarly, Gomes et al. [34] illustrate how ambidexterity is an important determinant of environmentally sustainable production in the area of quality management. Using a qualitative approach, instead, Minatogawa et al. [35] come to the same conclusions in their study of a small e-commerce company.

The relevance of the topics of sustainability and ambidexterity in the banking industry context is well known. Financial services offered by banks can be considered transformative services [36], indispensable components of the social infrastructure, whose changes and development over time can trigger wide-range socioeconomic change. On a macroeconomic scale, the composition of their investment portfolios affects both the pace and composition of economic development, while the development of new financial instruments can either support or undermine financial stability. Technological changes, such as digitalization, can also bring substantial social consequences. Wang and He [37] illustrate how digital access to banking services decrease the vulnerability to risk of poor farmers in China, while Yeo and Jun [38] show how P2P lending is changing credit conditions for borrowers with low-to-mid credit ratings.

As service firms, banks rely on intangible assets and knowledge to provide a superior customer experience [39]. Innovative activity is required for the economic sustainability of banks and the maintenance of their competitive advantage [40]. The banking industry has witnessed fundamental changes and greater instability that heighten the importance of successfully attaining ambidexterity to increase their performance [41]. Following the intensified competition brought by the gradual process of deregulation that has taken place in the last decades, bank units are expected to constantly improve existing products while also reducing costs by optimizing current operations. To meet these challenges, banks have integrated advances in information and communication technologies to introduce process technologies, increasing internal efficiency and improving productivity. The need to merge digital innovation with banking operations, however, have led to the emergence of new challenges for the development of ambidexterity in banking.

Studying the implementation of sustainable business models in banking, Yip and Bocken [42] notice the practical relevance of short-termism: the tendency to evaluate innovative projects predominantly on their ability to generate value in the short-term. In this sense, digitalization is often preferred because of its potentially calculable benefits, and its relative quick scalability. However, Marabelli et al. [43] document how large banks, with activities dispersed over large territories, facing the challenge to conjugate the need for innovation with the constraints of the short term, are likely to adapt ambitious ambidextrous organizational approaches, despite the additional managerial and organizational costs involved. Ambidexterity is found to require a managerial approach based on trust and decentralization in boundary activities, confirming the importance of managerial leadership [44,45] and a trust-based culture [21,46] as antecedents. Although somewhat animated by short-term considerations, the digitalization process is also promoting the development of ambidextrous capabilities, thus improving the general ability of financial firms to engage in the transformation processes required by sustainability (new references mentioned before). Thus, although superficially separated, the development of ambidexterity can be understood as an intermediate step in the gradual transformation of financial services towards more sustainable configurations.

In conclusion, the literature reviewed reveals that sustainability in the banking industry requires the integration of ambidextrous business models. The questions of which type of ambidexterity is preferable and how should it be implemented remain open, however. Furthermore, actual implementation of new operational routines and innovationsupporting tools appears particularly challenging in the heavily regulated and risk-averse environment of large-scale banking. As low-interest rates persist and digital-based innovative competitors enter the market; however, the challenge of ambidexterity must be met if traditional banking is to retain its central position within the global financial infrastructure. 


\section{Methods}

This paper introduces a study of an on-going digital transformation in a large Norwegian bank. More specifically, we examine the issue through a case study of a large financial organization-DNB - currently transitioning from a traditional bank business model towards a technology-based provider of financial services. DNB is Norway's largest financial services group and one of the largest in the Nordic region in terms of market capitalization. They offer services to corporate, retail, and securities markets as well as the public sector. In addition to being a world leader in shipping, the bank has a strong position in the energy sector and seafood industries, reflecting traditional Norwegian economic strengths. As one of the largest financial institutions in the Nordic region, our case company is an excellent exemplar of an incumbent undergoing digital transformation while intending to retain its dominant market position.

We conducted semi-structured interviews with key stakeholders across operations to gain in-depth insight into organizational members' reasoning and reflections. This allowed us to comprehend the logic through which they viewed the world [47]. Furthermore, indepth interviews provide an effective means of obtaining rich insights into the phenomenon of interest, as they provide access to detailed contextual information and individual insight that cannot be obtained from surveys [48]. The informants were identified first through expert sampling, and then through snowball sampling, ensuring that all protagonists of the process have been interviewed, and their perspective integrated.

The respondents consisted of 12 managers directly involved in the company's innovation initiatives. They ranged from VP-level to middle management responsible for strategic innovation projects or programs across all DNB areas: New Business (5 respondents), Corporate Market (1 respondent), Consumer Market (2 respondents), Key Accounts (1 respondent), and IT (3 respondents). Within these areas, there are several divisions-referred to as "Innovation divisions" in New Business, "IT divisions" in IT, and "Business divisions" in the remaining areas.

Interviews were conducted until information redundancy was achieved [49]. We used semi-structured interview guides (see Appendix A), allowing for deviation from the sequence in order to follow interesting lines of inquiry and go deeper into relevant, emerging, topics. The approach was deemed particularly appropriate to this case study, since the company was undergoing a complex transformation process, leaving many informants to face significant, persistent uncertainty, which showed in their difficulties to engage directly with our questions. The questions covered the company's existing practices at the time of interview, personal experiences with and interpretations of innovation capabilities and tools, processes and resources, culture and values related to innovation initiatives. Interviews lasted for 45 to $60 \mathrm{~min}$; they were digitally recorded and transcribed verbatim.

To structure respondent explanations and interpretations, we inductively examined our data by following the procedure suggested by Gioia and co-authors [50,51], a method considered particularly appropriate for research on strategic change and sensemaking [52]. In the first stage, we developed "open" codes by uncovering initial concepts from respondents' statements. Then, we confronted our results and integrated them, prioritizing adherence to the respondents' opinions in order to solve controversies. In the second stage, we classified these into higher order themes through axial coding based on the relationships among the initial first-order codes, translating the empirical results into relevant theoretical constructs. Finally, we gathered similar themes into aggregate dimensions that provided an overall structure to our narrative. We performed this procedure iteratively, going back and forth between codes and data until consensus among the authors emerged. Figure 1 shows the final data structure. The vertical order of the aggregate dimensions offers a broad timeline of the process of implementation of ambidexterity capabilities, starting from original situation and the initial plan, moving gradually towards a blended approach directed towards a reciprocal outcome. This narrative emerged during reflexive discussion between the authors and was subsequent used to organize the exposition of empirical 
results. The following discussion provides a reconstruction and a potential explanation of the phenomenon in theoretical terms, illustrating which elements are consistent with existing literature, and which ones can be interpreted as an original contribution.

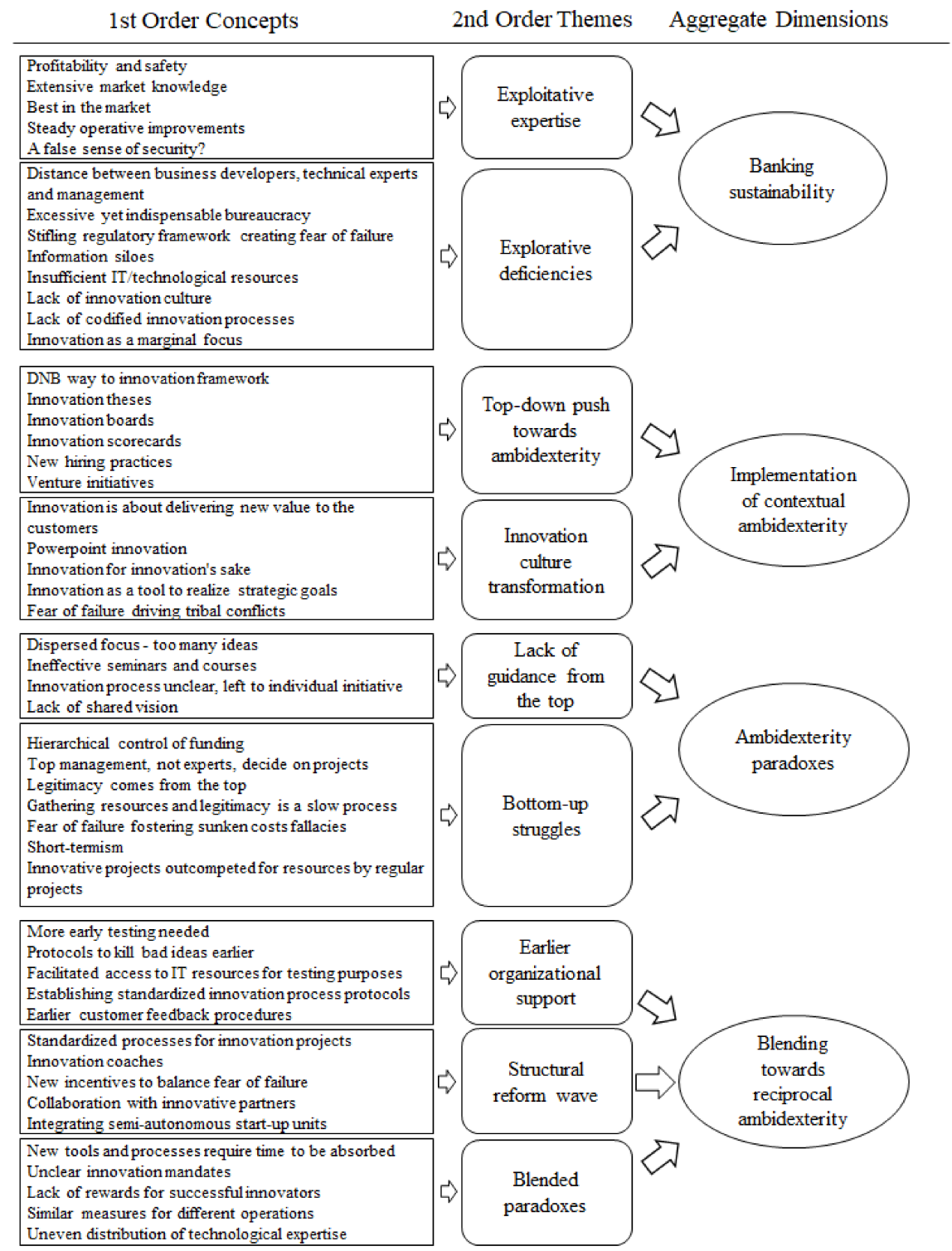

Figure 1. Data structure.

\section{Results}

\subsection{Banking Sustainability}

Most respondents contextualized the current organizational reform process affecting $\mathrm{DNB}$ as a reaction to a situation of complacency. The secure oligopolistic position held by DNB within the Norwegian financial market ensures comfortable profit margins, superior to most European counterparts, margins that are not currently under significant threat from the local competition. The management however is conscious of the fact that such rosy situation is unlikely to last indefinitely:

"I don't think we're going to be out-competed, but I probably think the margins within some of our most profitable business models is going to come under increasing pressure then in the years to come, and that requires us to innovate our existing business models, we need to become more efficient in streamlining our operations." —Division Director IT Division. 
Lack of profitability pressures and steady profits have led to somewhat underdeveloped innovative capabilities:

"We are lacking some parts of what I would call innovation competence, such as pure business model innovation, experiment design and execution. We have some individuals, but not enough for a company of this size. When you look at traditional business development, how to treat an idea, how to actually build up partnerships, how to build services and products, we have that in house, but using it for innovation is a different issue." - Leader, Digital Innovation, B2C.

Furthermore, innovative resources and competences are not only relatively scarce, but also unevenly distributed and isolated:

“Our innovation capabilities are kind of spread between business developers with different types of roles. And then you have other sides of the innovation capabilities, IT and people of operations in different service roles, like service designers or literally IT architects." - Senior innovation coach.

The interviews underlined how DNB lacked company-wide systems for knowledge integration and sharing [53]. Respondents reported how they often struggled to access and share specialized knowledge across departments in an effective manner:

"DNB actually does have a lot of insight, but we have difficulties in terms of access across divisions (because we are legally not allowed to) and the systems that we use." - Senior innovation coach.

In addition to knowledge, all managers interviewed have described IT resources as similarly scarce and difficult to mobilize, mostly tied up in the maintenance of inherited old IT systems. The challenge appears to be particularly pronounced in connection to innovative activities:

"Our IT department is at all times 100\% sold out and over capacity, so that IT with today's setup does not have any capacity to assist in innovation work at all. It is due to the management model, and partly because IT has a rather heavy responsibility related to security, compliance, the Financial Supervisory Authority and other things." - IT Division Director.

\subsection{Implementation of Contextual Ambidexterity}

In reaction to these and other commonly perceived shortcomings, DNB has developed the "DNB Way of Innovation" strategy, in order to develop harmonic ambidexterity capabilities across the entire organization. This aim has been pursued through a series of top down reforms, supported by attempts directed towards a comprehensive organizational innovation culture transformation. Several top-down initiatives have been implemented on a company-wide level in order to become more innovative through the integration of more explorative methods, tools, and processes:

"I can't really say that we have a clearly defined innovation framework or strategy, but we do have some new initiatives (innovation boards). Moreover, we have something called 'The DNB Way of Innovation' with certain practices and tools that our innovation coaches should master quite well." —Section Leader, New Business Payments.

DNB is on a transformation journey from being a sheltered, oligopolistic financial institution to a global competitor in the digital innovation arena. This means that DNB must become more forward-looking and able to embrace failure as part of becoming more innovative. However, such a mindset shift is entirely at odds with traditional banking, a business model well-known for its conservative approach and strongly institutionalized aversion to failure. One of the informants reflected on this: 
"We are supposed to depart from a culture in which we make 'safe' decisions towards a culture where failure is allowed, and initiative is rewarded." - Section Leader, New Business Payments.

Although the aim is clear, the path remains challenging, however, with significant tensions emerging within and between departments [54]:

"There are a lot of people at the IT department at DNB who do not dare to fail, because there has been no room for failure in the past. It has been a fear-based culture. Even though our CEO says we should dare to fail the organization is rigged towards risk aversion." —-Leader, Accelerate Innovation-New Business.

\subsection{Ambidexterity Paradoxes}

Since DNB has only recently developed an innovation focus, with most of the processes still to be fully implemented, few employees have actual experience with innovation management practices. As many new tools and processes for innovation are introduced "from above", many informants still feel like their innovation projects are outcompeted on resources against regular projects. One of the respondents commented:

"Some of us are supposed to think innovative according to our scorecards yet we often get tied up to existing projects. I tell my employees to spend twothirds of their time on existing projects and one-third of their time on thinking forwards, but this is not how it works out in reality." - Section Leader New Business Payments.

The lack of dedicated resources and structures supporting innovative efforts from the bottom-up hampered the first attempts to apply the new strategy:

"I think the greatest potential for DNB is to innovate more on the things that we already have. We have a lot of new initiatives [... Y Yet, with few resources, time and capacity on continuous improvement there is a need for a better balance." -New Business, Accelerate Innovation.

One of the respondents reflected further on this part:

“We are often saying that 'hey, we would like to explore some of these opportunities' but then when you look how we invest, everything is core [...] that is not necessarily the problem, but if you say that you don't want to just do that, and then you do it, that might be a problem." - Senior innovation coach.

In response to these and other challenges, the company has established a new division called "New Business". This division works as a support department for the entire DNB Group, contributing its innovation expertise to other divisions focusing on traditional business areas. Furthermore, dedicated innovation coaches have been hired, to provide support to bottom-up innovation processes. The collaboration, however, is more difficult than expected, as the divide between those who innovates and those who do not becomes more pronounced:

"you sit with one foot on the gas and one on the brake. So, then I kind of think it's either go or no go. Either you feel that you are allowed to work with innovation as an employee, or you are one of those who feel that you are hired to make sure things do not go wrong." - Division Director of Innovation Division.

\subsection{Blending Towards Reciprocal Ambidexterity}

In order to alleviate some of the tensions described above, DNB is currently undergoing a second reform wave. One of the informants noted:

"The competence in innovation in the bank is still extremely low [...] That is why we have started this enterprise innovation program and created a separate division for design and innovation." - IT Division Director. 
Another solution to the lack of competence has been to prioritize external relationships. Explorative units engage in comprehensive collaborations with universities, other financial organizations, digital startups, and talented young programmers. Exploitative units absorb the knowledge so attained through internal training and seminars. By collaborating with innovative partners, introducing innovation coaches, and launching more standardized exploration processes, DNB is supporting the implementation of its Way of Innovation with decidedly structural changes. DNB has purchased "Luca Lab" to bolster the innovative capabilities of its DNB Accounting business unit. In addition, DNB has partnered with "11: FS" to develop a consumer finance solution ("Foundry").

The data reveals that, despite the initial harmonic plans, during the process of implementation the organization has blended different modes of ambidexterity [6], introducing structural solutions both within and across departments. The co-presence of various ambidexterity modes resulting in distinct management challenges and paradoxes across units and departments. The company struggles to obtain mechanisms for linking and integrating different modes of operation. In this regard, previous studies [22] have emphasized that separate units may embody distinct strategies and operating logics and even cultures, yet need to be coordinated through a shared vision animating the senior management team's actions:

"We notice that in very many of the discussions we have, there is a cultural difference. I believe in creating a common culture, common goals and a common understanding. So, even if someone is working with an agile approach and others are doing more waterfall-type work that it is perfectly fine as long as we are working towards some common organizational goals." —Leader, Digital Innovation, B2C.

Achieving such synergistic fusion, however, necessitates that different units work interdependently in terms of ambidexterity:

"There is a gap in terms of implementing that innovation strategy and framework and process in the organization. My impression is that there is little awareness of the innovation strategy amongst managers and employees in general in the organization at large." -IT Division Director.

According to most respondents, the main challenge currently faced by DNB in the process to further develop its innovative capabilities lies in the fact that significant amounts of resources are spent on the idea generation and early development phases of new products and services, before any attempts towards validation are made, resulting in significant sunk costs.

"Now, people have a thousand ideas, and everyone works with them for a year, and then you come to the IT team and do not get the resources to make it. We need to become much better at prioritizing in early stages of projects and say no to others, so that the things we actually choose to do we do properly with the right resources." -Division Director, Open Banking.

This has led to the implementation of practices aimed at earlier idea selection:

"One of the things that we try to work with in the innovation team is the number of ideas we are able to kill, the so-called 'kill-index', which is quite important. We have to teach the business areas that bad ideas are bad quicker." -New Business, Accelerate Innovation.

The reform involves the creation of dedicated testing units and resource pools, accompanied by a concerted effort to promote a testing culture: "So we are really pushing the testing culture in the whole of DNB, building up a testing environment where you can actually, everyone and I am not talking about Private Market only, but that all DNB, IT, everyone is using the same platform, in terms of sharing their learnings."-Section Leader, Private Market-Digital Sales. 
The informants have also mentioned the lack of a rewards system for innovation efforts: current incentives in the bank follow traditional practices. In this regard, $\mathrm{O}^{\prime}$ Reilly and Tushman [55] emphasize the importance of rewarding cross-unit accomplishments tied to growth targets instead of specific unit goals. As incentive structures and operative realities drift further apart, the opportunities for new paradoxes to arise increase.

These findings suggest that DNB is transitioning towards reciprocal ambidexterity, with different units operating partially independent-attempting to obtain the synergistic fusion of complementary streams of exploitation and exploration as depicted by Simsek et al. [20]. According to Brix [19], the main difference between reciprocal ambidexterity and partitional ambidexterity is that reciprocal ambidexterity is characterized by processes of transferring knowledge back and forth between two separate units. Simsek et al. [20] assert that this type of ambidexterity is more likely to emerge in complex environments-which certainly is descriptive for DNB as an organization.

By transitioning between multiple modes of ambidexterity several paradoxes have appeared to the surface. Structural reforms and company-wide change processes take time to complete, and unforeseen challenges are almost inevitable in a large an organization as DNB. Unclear mandates for innovation, uneven distribution of resources, especially IT, and the lack of a distinct reward system for innovation exemplify some of the paradoxes and inconsistencies that have emerged in a transitional ambidexterity process. We illustrate the trajectory path of transitional ambidexterity at DNB in Figure 2.

\section{Structural dimension}

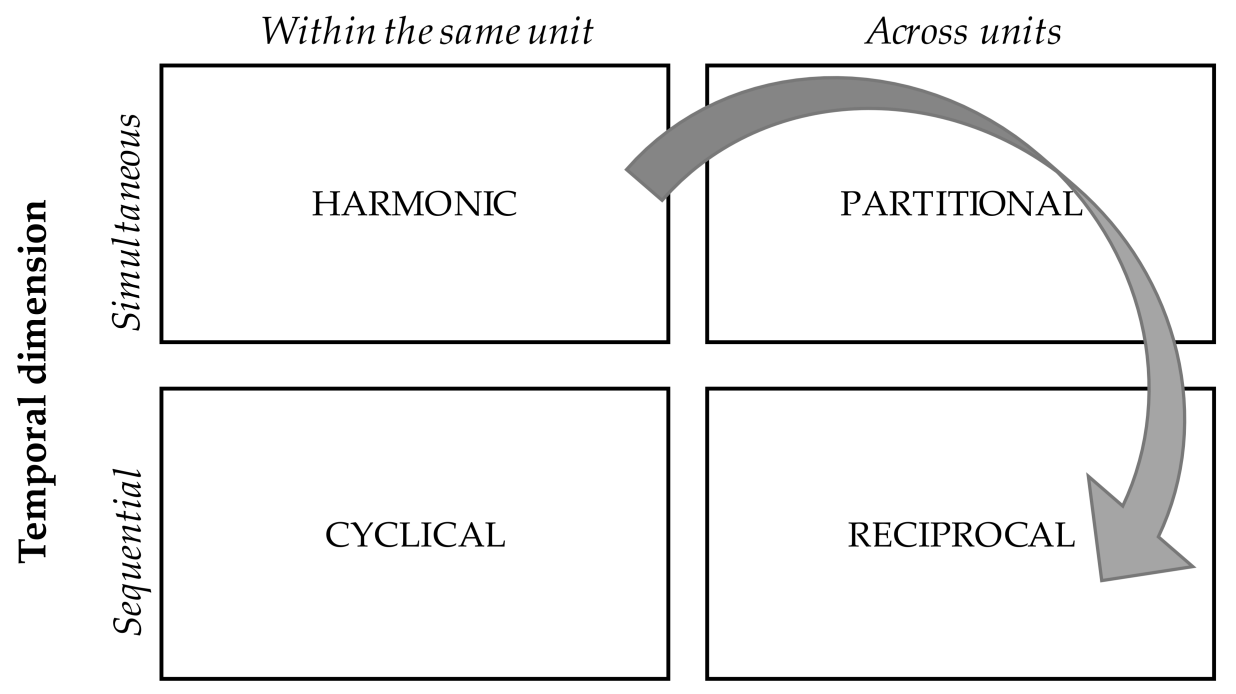

Figure 2. Suggested trajectory of transitional ambidexterity at DNB; from harmonic to reciprocal. The figure is an adapted version of organizational ambidexterity typology, as introduced by Simsek et al. [20] (p. 868).

\section{Discussion}

The implementation of the DNB Way of Innovation strategy is ongoing and, given the experimental, reflexive, and flexible approach undertaken by the top management in its realization, its long-term results cannot be fully appreciated today. What the DNB case can teach us, however, is how, while ambidextrous capabilities can be developed and an ambidexterity strategy planned, its implementation will confront management with certain realities imposing a specific direction to organizational reform, no matter the original intentions. Not only are these findings relevant for our understanding of the development of ambidexterity through time, it also matters for our analytical application of the various types of ambidexterity discussed in the literature. The emergence of specific ambidextrous practices through time have also important implications for the question of the sustainability of banking business models in the long term. 
In this regard, it is notable how neither present profitability, nor a strong market position, have blinded DNB management to the need for developing an ambidextrous stance in order to ensure long-term economic sustainability. All our informants, no matter how critical of the bank or its strategies, agreed on this point. A similar consensus was obtained in regard to the satisfactory performance of the exploitative activities of the firm, and its much less adequate explorative capabilities. Consequently, to achieve an ambidextrous stance, a comprehensive reform of the innovation processes of DNB was needed; this is what the DNB Way of Innovation is attempting to deliver.

The key aim of the new model is to achieve higher organizational explorative capabilities by fostering the development of individual innovative ability among the general workforce and, over time, within every business unit [56]. Employees are asked to devote an increasing amount of their time and attention to explorative activities in addition to routine exploitative tasks. Management is asked to support this shift by integrating a variety of new tools and processes developed to support bottom-up innovation processes, by allocating resources to such initiatives and by supporting the gradual diffusion of innovative expertise and an innovation-friendly culture. While digital technologies are involved in most innovative projects, the strategy itself is agnostic regarding content: any proposal able to satisfy the requirements defined by the strategy and to gain the relevant managerial support is welcome. The aim is to improve the general explorative capabilities of the firm, rather than achieving a specific technological or market objective; a choice not without consequences.

Although not labeled as such, the initial strategy has clearly been one of fostering contextual, or harmonic, ambidexterity among several business units. This aim has been pursued through the implementation of new practices and instruments, meant to both support the development of existing innovative projects and ideas, and to foster a more general shift toward an organizational culture more supportive of innovative individual initiatives. The chosen approach reveals an understanding on part of the reformers of the importance of a supporting organizational culture for contextual ambidexterity to be successfully developed, as argued by Wang and Rafiq [21]. However, the implementation of this consistent and theoretically sound plan reveals some inherent limitations.

Contextual ambidexterity encourages bottom-up innovation initiatives. However, especially in the initial phases of a transition towards a more established ambidextrous modus operandi, the burden of such efforts falls almost entirely on the shoulders of the innovative individuals involved. The paradox of ambidexterity highlighted here is that, while individual initiative is encouraged, it is only rewarded in case of success, if at all. The rate of success of innovative projects, however, is always very low; in a context in which explorative capabilities are lacking, and new instruments still being experimented with, the probabilities of success can be described as abysmal. Thus, those individuals open to innovation, receptive to encouragement, and hard-working and risk-tolerant enough to try and kickstart an innovative idea while still keeping up with their daily routine, are likely to encounter uncertainty, frustrations, and, ultimately, failure [57].

This undesirable outcome can be managed, but not entirely avoided. Establishing instruments, practices, and cultural norms able to support reiterated individual failure is a necessary goal on the road of establishing contextual ambidexterity capabilities. In the initial stages, however, the goal of fostering bottom-up initiatives in order to test the approach overrides any other concern, leading, in the best-case scenario, to a proliferation of ideas and new projects to be managed. The newly established and still experimental practices and tools are unlikely to be successful in providing sufficient support to all of them. Selection is necessary and yet, paradoxically, undesirable [58]. Employees are already asked to promote innovative ideas in addition to their normal tasks: to push severe requirements on such ideas is likely to result in very few projects being generated. While the low number of projects may very well be in line with initial managerial capabilities, an optimal outcome even, it may also delegitimize the ambidexterity reform, undermining 
the proponents in the eyes of top management. Better to let a hundred flowers bloom; the cruel harvest may come later.

Other paradoxes emerge in regard to the issue of organizational culture. If individual employees are to be free to pursue explorative activities, their managers must be willing and able to support such decisions. This requires the adoption of a perspective favorable to contextual/harmonic ambidexterity, and the acceptance of the organizational value of the new tools and practices which such approach entails. However, different business units will have different perspectives on the relative importance of bottom-up innovation processes for the sustainability of their operations. Thus, the single innovation vision promoted from the top will shatter into several different interpretations during the process of implementation. The understanding of what innovation is, how it should be pursued, and what it could achieve was extremely heterogeneous across organizational lines. This is not simply a matter of opinions: the role of management in supporting contextual/harmonic ambidexterity is key [59]. While new tools, practices, and lingo can be adopted as a result of a push from the top, their effectiveness will vary greatly according to the actual support that local management is willing to offer to the new innovative projects, a key factor in the tender early stages of the process.

However, these cultural differences are not created by reform attempts, but rather brought to light. The resulting discussions and attrition play two constructive roles. First, they promote a debate that, in the long term, can lead to a more homogeneous organizational culture. Second, managerial criticism may reveal flaws and limitations of the original strategy, either specific to a given business area or general, an input that, if constructively received, can lead to general improvements in ambidexterity capabilities. The paradox lies in the fact that, in the short term, attempts to foster a homogenous innovation culture will highlight the fractured condition of the organization [60].

Ultimately, these tensions will lead to a struggle for resources, the practical embodiment of the conflict between exploitative and explorative activities [61]. The initial push supporting bottom-up initiative provides enterprising employees with the possibility to allocate some of their work time to ideating an innovative project. Any serious development, however, would require additional resources; however, under contextual/harmonic ambidexterity, resources are not specifically allocated to exploration or exploitation, they are flexibility redistributed according to needs. This means that bottom-up initiatives must constantly leverage their resources into access to more resources, climbing the managerial pole one meeting at a time. While the initial competition will be with other innovative initiatives, eventually explorative and exploitative needs will come to a clash. From an organizational perspective, this conflict is both inevitable and desirable: the ability to constructively and efficiently solve such conflicts is contextual ambidexterity. It is clearly an unfair fight, as the necessity and benefits of exploitation are well known, while the gains of exploration are by nature uncertain. Furthermore, resources for innovative projects often must be gathered across organizational lines, with the resulting organizational culture differences further stacking the deck against the explorative alternative.

The situation is worsened by the early tolerance necessary for the testing phase to begin in earnest. A hundred flowers bloom, but very few give fruit: the early impression of vigor later gives rise to disappointment among the would-be innovators and a general perception of wasted time, efforts, and resources among all involved. Two solutions to this problem can be adopted; in our case, both roads have been travelled. The first is providing more support to the innovators, to allow them to fight more effectively for the resources they need. The second is to create resource pools dedicated exclusively to explorative purposes, thus alleviating the need to compete with exploitative activities. These solutions to the quintessential contextual ambidexterity issue, however, are clearly structural in nature [62]. The former implies the creation of groups and organizational divisions dedicated entirely to explorative support; the latter makes the critical allocation of resources decision an ex ante managerial prerogative, coming from the top rather than being endogenously defined by bottom-up initiatives. While such an organizational response is not necessary, the issues 
it addresses are implied by any contextual/harmonic strategy. The choice appears to be either to accept the paradoxes of contextual ambidexterity, and the organizational costs they imply, or to try and fix the situation by blending in structural solutions.

The contextual/structural axis is not the only one that begins to blur, however. Integrating a time perspective, it is possible to see that the DNB Way of Innovation intended to pursue a harmonic strategy, integrating exploration as a continuous focus over time [63]. However, the bottom-up, decentralized nature of contextual ambidexterity, combined with the broad integration of such practices over all business units, implies that the actual ratio of resources engaged in exploration vs. exploitation cannot be planned for in advance. Since most initiatives can be expected to fail in their early stages, most resources can be expected to be spent on exploitative routines. However, exceptional projects will arise from time to time, commanding a significant amount of internal resources. To be realized, such projects will eventually need to access resources across business units' lines, forcing other units to play a supporting role. At the same time, other units will have to pick up the exploitative slack, covering for the missing input for the temporarily explorative unit. Furthermore, as the innovation process develops, the initial unit may de-escalate its involvement, as other units with different capabilities and responsibilities take over the lead.

From a theoretical perspective, this description can be summarized in the following proposition: the implementation of a harmonic ambidexterity strategy within a large organization will lead to reciprocal ambidexterity in practice. The process will be supported by a gradual blending of contextual and structural elements, the latter introduced to diffuse the tensions emerging from the former. The argument can be seen as an extension of Andriopolous and Lewis' [64] argument in favor of a multilevel approach: structural and contextual ambidexterity are complementary strategies, covering each other's limitations. This does not mean that the resulting blend is devoid of paradoxes and tensions: our results already reveal several emergent issues. It is likely that such issues will drive further changes in the strategy. This reinforces our argument further: implementation challenges, and their solutions, drive the development of ambidexterity capabilities, in an evolutionary, path-dependent process illustrated in Figure 3, in which teleology can play only the role of trigger [65]. However, does this process ensure corporate sustainability?

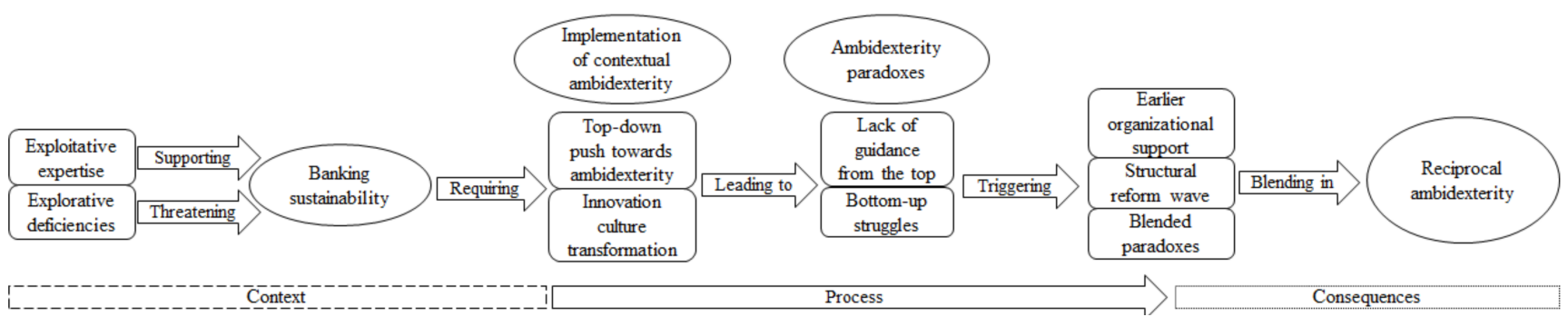

Figure 3. Transitioning from harmonic to reciprocal ambidexterity.

Of the various components of the corporate sustainability construct, economic, environmental, social, operational, and strategic, all are involved within the process under study, with one key exception. Strategic sustainability can be seen as the main aim of developing ambidexterity capabilities. Economic sustainability is improved by ensuring that a concern for maintaining the competitive advantage over time is diffused among all organizational units and levels. Operational sustainability is supported by the reflexive practices supporting the development of innovative capabilities. Social sustainability is also improved, through expansion of collaborative explorative initiatives involving external firms and organizations and by integrating customer feedback in the early stages of the innovation process. What remains outside this process, however, is environmental sustainability. The ongoing digitalization effort will have some modest positive consequences on the environmental blueprint of the immediate bank activities, but this is accidental: as discussed above, the ambidexterity process is technologically agnostic. We have found 
no evidence of significant environmental sustainability concerns at any organizational level, nor was the issue mentioned as particularly significant for the future of the firm at large. This blind spot will need to be addressed in the future, as the relevance of the environmental aspects of sustainability will come to play an increasingly larger role in the future [66].

\section{Conclusions}

The literature on ambidexterity has identified a number of alternative solutions to the need of the firm to simultaneously engage in exploitative and explorative tasks in order to secure its sustainability. Recent research has suggested that these solutions may not be alternatives, but they can be in fact simultaneously pursued, in different mixes. We add to this result by supporting the hypothesis that the limitations inherent in a specific ambidextrous solution, namely, contextual ambidexterity, create conditions that both invite and facilitate the introduction of structural solutions. Thus, a reflexive process of implementation is likely to result in blending harmonic and partitional approaches. Furthermore, we have provided evidence suggesting that, over time, the same process of addressing emerging practical issues may lead to the emergence of reciprocal ambidexterity, the most complex configuration identified by the literature.

Our research contributes to the existing literature by adding a temporal dimension to the analysis of blended ambidexterity, and by integrating the dynamic concept of blending with the static conceptual taxonomies of the ambidexterity construct. From a practical perspective, we argue that, in dealing with an inherently paradoxical phenomenon such as ambidexterity, internal consistency in planning should be sacrificed to operational flexibility and the emerging need revealed by the process of implementation: the resulting hybrid may well be more successful than its theoretical pure counterpart. From a theoretical perspective, we analyze the phenomenon of blending over time, and its consequences for our conceptualization of the phenomenon of ambidexterity. Furthermore, we question the analytical validity of imposing dualistic structure to a phenomenon that appears to be empirically dominated by crossed lines.

The research is characterized by a number of limitations. Firstly, we did not interview lower level employees; A more comprehensive approach in the gathering of data would strengthen the research and open new vistas on the bottom up struggles that characterize any attempt at fostering contextual ambidexterity. Secondly, although clear reciprocal signs are in evidence, the stability of this configuration cannot be taken for granted. On the basis of current evidence, we believe that such configuration may be reasonably assumed to be the final form that ambidexterity will take in DNB, at least in the medium-term. The validity of such assumption should however be tested by future research. Third, while the role of ambidexterity as an antecedent of sustainability is in our view sufficiently established, the actual mechanisms linking ambidextrous capabilities with the development of sustainable business practices should be subject to more direct investigation, something we were prevented from doing by the presently modest attention dedicated by the subject of our study to these concerns.

Author Contributions: Conceptualization, B.C. and R.S.R.; methodology, R.S.R; formal analysis, B.C. and R.S.R.; data curation, R.S.R.; writing — original draft preparation, B.C. and R.S.R; writing-review and editing, B.C. and R.S.R.; visualization, B.C. and R.S.R; supervision, B.C.; project administration, R.S.R.; All authors have read and agreed to the published version of the manuscript.

Funding: This research received no external funding.

Institutional Review Board Statement: Not applicable.

Informed Consent Statement: Informed consent was obtained from all subjects involved in the study.

Acknowledgments: We would like to thank Amir Saed Ali, Arman Muzaffar, and Rehan Yousaf for their help with data collection.

Conflicts of Interest: The authors declare no conflict of interest. 


\section{Appendix A. Interview Guide}

Resources: People and competence

How is the composition of people and competence in your division/section when it comes to innovation?

\section{Time and resource allocation}

What are your views on how time and other resources are allocated to activities related to innovation, exploration, reflection and problem solving, in your division?

\section{Tools and frameworks}

Are there any tools or frameworks available to manage and evaluate innovation?

Understanding of innovation

Do you perceive that DNB and your division understand what innovation is, its significance and how to work on it?

\section{Competition and market position}

Does DNB, and your division, know how the market is structured and how to compete in it?

\section{Processes}

Do you perceive that your division is making sufficient efforts to explore new business or technological possibilities?

\section{Incubation}

Are there effective ways to incorporate new ideas or solutions into the organization and subsequently implement them in products or customer offerings?

Learning and unlearning

Has the divisions worked to promote, rearrange or change the competence and capabilites in the organization to become competitive in a changing market?

\section{Bureaucracy}

Do you perceive that the inherent organizational bureaucracy is inhibiting how you work with innovation?

\section{Innovation strategy}

Do you perceive that there is a clear strategy for innovation, and is it known among the employees?

\section{Strategy vs. operational}

Do you feel that the innovation activity in your divisions is derived from or linked to one common innovation strategy in the organization?

\section{Culture for creativity}

Are creative solutions or unconventional ideas encouraged - and are they explored or implemented by your division?

Organizational dependencies

How does your division handle issues of being relevant both technologically and business wise-and how do you consider future opportunities?

\section{Decision basis and rules for innovation}

Do you perceive rules for decision making and evaluation of new ideas to be clear and suitable for enabling innovation?

\section{External relations}

How does how your division collaborate with or evaluate external actors to enable innovation?

Clear decisions and division of responsibilities

Is it clear and appropriate how the mandate and responsibilities for innovation are assigned in our division?

\section{In general}

What do you think are the most important factors that enable/inhibit innovation in your division?

\section{References}

1. Atuahene-Gima, K. Resolving the Capability-Rigidity Paradox in New Product Innovation. J. Mark. 2005, 69, 61-83. [CrossRef] 
2. Gupta, A.K.; Smith, K.G.; Shalley, C.E. The Interplay Between Exploration and Exploitation. Acad. Manag. J. 2006, $49,693-706$. [CrossRef]

3. Gibson, C.B.; Birkinshaw, J. The antecedents, consequences, and mediating role of organizational ambidexterity. Acad. Manag. J. 2004, 47, 209-226.

4. Duncan, R.B. The ambidextrous organization: Designing dual structures for innovation. Manag. Organiz. 1976, 1, 167-188.

5. Nickerson, J.; Zenger, T.R. Being Efficiently Fickle: A Dynamic Theory of Organizational Choice. Organ. Sci. 2002, 13, 547-566. [CrossRef]

6. Foss, N.J.; Kirkegaard, M.F. Blended ambidexterity: The copresence of modes of ambidexterity in William Demant Holding. Long Range Plan. 2020, 53, 102049. [CrossRef]

7. Nosella, A.; Cantarello, S.; Filippini, R. The intellectual structure of organizational ambidexterity: A bibliographic investigation into the state of the art. Strat. Organ. 2012, 10, 450-465. [CrossRef]

8. O'Reilly, C.A., III; Tushman, M.L. Organizational ambidexterity: Past, present, and future. Acad. Manag. Perspect. 2013, 27, 324-338. [CrossRef]

9. Smith, W.K.; Lewis, M.W. Toward a theory of paradox: A dynamic equilibrium model of organizing. Acad. Manag. Rev. 2011, 36, 381-403.

10. Hill, S.A.; Birkinshaw, J. Ambidexterity and Survival in Corporate Venture Units. J. Manag. 2014, 40, 1899-1931. [CrossRef]

11. Khan, Z.; Lew, Y.K. Post-entry survival of developing economy international new ventures: A dynamic capability perspective. Int. Bus. Rev. 2018, 27, 149-160. [CrossRef]

12. Levinthal, D.A.; March, J.G. The myopia of learning. Strat. Manag. J. 1993, 14, 95-112. [CrossRef]

13. March, J.G. Exploration and Exploitation in Organizational Learning. Organ. Sci. 1991, 2, 71-87. [CrossRef]

14. Tushman, M.L.; O'Reilly, C.A., III. Ambidextrous organizations: Managing evolutionary and revolutionary change. Calif. Manag. Rev. 1996, 38, 8-29. [CrossRef]

15. Adler, P.S.; Goldoftas, B.; Levine, D.I. Flexibility Versus Efficiency? A Case Study of Model Changeovers in the Toyota Production System. Organ. Sci. 1999, 10, 43-68. [CrossRef]

16. Raisch, S.; Birkinshaw, J. Organizational Ambidexterity: Antecedents, Outcomes, and Moderators. J. Manag. 2008, 34, 375-409. [CrossRef]

17. Smith, W.K.; Tushman, M.L. Managing Strategic Contradictions: A Top Management Model for Managing Innovation Streams. Organ. Sci. 2005, 16, 522-536. [CrossRef]

18. Caniëls, M.C.; Neghina, C.; Schaetsaert, N. Ambidexterity of employees: The role of empowerment and knowledge sharing. J. Knowl. Manag. 2017, 21, 1098-1119. [CrossRef]

19. Brix, J. Ambidexterity and organizational learning: Revisiting and reconnecting the literatures. Learn. Organ. 2019, 26, 337-351. [CrossRef]

20. Simsek, Z.; Heavey, C.; Veiga, J.F.; Souder, D. A typology for aligning organizational ambidexterity's conceptualizations, ante-cedents, and outcomes. J. Manag. Stud. 2009, 46, 864-894. [CrossRef]

21. Wang, C.L.; Rafiq, M. Ambidextrous Organizational Culture, Contextual Ambidexterity and New Product Innovation: A Comparative Study of UK and Chinese High-tech Firms. Br. J. Manag. 2012, 25, 58-76. [CrossRef]

22. Benner, M.J.; Tushman, M.L. Exploitation, Exploration, and Process Management: The Productivity Dilemma Revisited. Acad. Manag. Rev. 2003, 28, 238. [CrossRef]

23. Thompson, J.D. Organizations in Action: Social Science Bases of Administration Theory; McGraw-Hill: New York, NY, USA, 1967.

24. O'Reilly, C.A., III; Tushman, M.L. Ambidexterity as a dynamic capability: Resolving the innovator's dilemma. Res. Organ. Behav. 2008, 28, 185-206. [CrossRef]

25. Jansen, J.J.; George, G.; Van den Bosch, F.A.; Volberda, H.W. Senior team attributes and organizational ambidexterity: The moderating role of transformational leadership. J. Manag. Stud. 2008, 45, 982-1007. [CrossRef]

26. Dyllick, T.; Hockerts, K. Beyond the business case for corporate sustainability. Bus. Strat. Environ. 2002, 11, 130-141. [CrossRef]

27. Moneva, J.M.; Archel, P.; Correa, C. GRI and the camouflaging of corporate unsustainability. Account. Forum 2006, 30, $121-137$. [CrossRef]

28. Moneva, J.M.; Ortas, E. Corporate environmental and financial performance: A multivariate approach. Ind. Manag. Data Syst. 2010, 110, 193-210. [CrossRef]

29. Schaltegger, S.; Burritt, R. Corporate sustainability. In The International Yearbook of Environmental and Resource Economics 2005/2006A Survey of Current Issues; Folmer, H., Tietenberg, T., Eds.; Edward Elgar: Cheltenham, UK, 2005.

30. Smith, J.; Haniffa, R.; Fairbrass, J. A conceptual framework for investigating 'capture' in corporate sustainability reporting as-surance. J. Bus. Ethics 2011, 99, 425-439. [CrossRef]

31. Sulphey, M.; Alkahtani, N.S. Organizational ambidexterity as a prelude to corporate sustainability. J. Secur. Sustain. Issues 2017, 7. [CrossRef]

32. Hahn, T.; Pinkse, J.; Preuss, L.; Figge, F. Ambidexterity for Corporate Social Performance. Organ. Stud. 2015, 37, $213-235$. [CrossRef]

33. Ciasullo, M.V.; Montera, R.; Cucari, N.; Polese, F. How an international ambidexterity strategy can address the paradox perspective on corporate sustainability: Evidence from Chinese emerging market multinationals. Bus. Strat. Environ. 2020, 29, 2110-2129. [CrossRef] 
34. Gomes, P.J.; Silva, G.M.; Sarkis, J. Exploring the relationship between quality ambidexterity and sustainable production. Int. J. Prod. Econ. 2020, 224, 107560. [CrossRef]

35. Minatogawa, V.; Franco, M.; Durán, O.; Quadros, R.; Holgado, M.; Batocchio, A. Carving out New Business Models in a Small Company through Contextual Ambidexterity: The Case of a Sustainable Company. Sustainability 2020, 12, 2337. [CrossRef]

36. Anderson, L.; Ostrom, A.L.; Corus, C.; Fisk, R.P.; Gallan, A.S.; Giraldo, M.; Mende, M.; Mulder, M.; Rayburn, S.W.; Rosenbaum, M.S.; et al. Transformative service research: An agenda for the future. J. Bus. Res. 2013, 66, 1203-1210. [CrossRef]

37. Wang, X.; He, G. Digital Financial Inclusion and Farmers' Vulnerability to Poverty: Evidence from Rural China. Sustainability 2020, 12, 1668. [CrossRef]

38. Yeo, E.; Jun, J. Peer-to-Peer Lending and Bank Risks: A Closer Look. Sustainability 2020, 12, 6107. [CrossRef]

39. Junni, P.; Sarala, R.M.; Taras, V.; Tarba, S.Y. Organizational Ambidexterity and Performance: A Meta-Analysis. Acad. Manag. Perspect. 2013, 27, 299-312. [CrossRef]

40. Roberts, P.W.; Amit, R. The Dynamics of Innovative Activity and Competitive Advantage: The Case of Australian Retail Banking, 1981 to 1995. Organ. Sci. 2003, 14, 107-122. [CrossRef]

41. Jansen, J.J.; Simsek, Z.; Cao, Q. Ambidexterity and performance in multiunit contexts: Cross-level moderating effects of structural and resource attributes. Strat. Manag. J. 2012, 33, 1286-1303. [CrossRef]

42. Yip, A.W.; Bocken, N.M. Sustainable business model archetypes for the banking industry. J. Clean. Prod. 2018, 174, 150-169. [CrossRef]

43. Marabelli, M.; Frigerio, C.; Rajola, F. Ambidexterity in Service Organizations: Reference Models from the Banking Industry. Ind. Innov. 2012, 19, 109-126. [CrossRef]

44. Beckman, C.M. The Influence of Founding Team Company Affiliations on Firm Behavior. Acad. Manag. J. 2006, 49, 741-758. [CrossRef]

45. Lubatkin, M.H.; Simsek, Z.; Ling, Y.; Veiga, J.F. Ambidexterity and Performance in Small-to Medium-Sized Firms: The Pivotal Role of Top Management Team Behavioral Integration. J. Manag. 2006, 32, 646-672. [CrossRef]

46. Cegarra-Navarro, J.-G.; Jimenez-Jimenez, D.; Garcia-Perez, A. An Integrative View of Knowledge Processes and a Learning Culture for Ambidexterity: Toward Improved Organizational Performance in the Banking Sector. IEEE Trans. Eng. Manag. 2019, 1-10. [CrossRef]

47. McCracken, G. The Long Interview; SAGE Publications, Inc.: Newbury Park, CA, USA, 1988.

48. Gwinner, K.P.; Gremler, D.D.; Bitner, M.J. Relational Benefits in Services Industries: The Customer's Perspective. J. Acad. Mark. Sci. 1998, 26, 101-114. [CrossRef]

49. Lincoln, Y.S.; Guba, E.G. Naturalistic Inquiry; Sage: Newbury Park, CA, USA, 1985.

50. Corley, K.G.; Gioia, D.A. Identity ambiguity and change in the wake of a corporate spin-off. Adm. Sci. Q. 2004, 49, 173-208.

51. Gioia, D.A.; Price, K.N.; Hamilton, A.L.; Thomas, J.B. Forging an Identity: An Insider-outsider Study of Processes Involved in the Formation of Organizational Identity. Adm. Sci. Q. 2010, 55, 1-46. [CrossRef]

52. Langley, A.; Abdallah, C. Templates and Turns in Qualitative Studies of Strategy and Management. In Building Methodological Bridges; Emerald: Bingley, UK, 2011; Volume 6, pp. 201-235.

53. Tiwana, A. Do bridging ties complement strong ties? An empirical examination of alliance ambidexterity. Strat. Manag. J. 2008, 29, 251-272. [CrossRef]

54. Papachroni, A.; Heracleous, L.; Paroutis, S. In pursuit of ambidexterity: Managerial reactions to innovation-Efficiency tensions. Hum. Relat. 2016, 69, 1791-1822. [CrossRef]

55. O'Reilly, C.A., III; Tushman, M.L. The ambidextrous organization. Harv. Bus. Rev. 2004, 82, 74. [PubMed]

56. Ahammad, M.F.; Lee, S.M.; Malul, M.; Shoham, A. Behavioral ambidexterity: The impact of incentive schemes on productivity, motivation, and performance of employees in commercial banks. Hum. Resour. Manag. 2015, 54 (Suppl. S1), s45-s62. [CrossRef]

57. Hansen, E.G.; Wicki, S.; Schaltegger, S. Structural ambidexterity, transition processes, and integration trade-offs: A longitudinal study of failed exploration. RED Manag. 2018, 49, 484-508. [CrossRef]

58. Smith, S.M. Organizational Ambidexterity: Welcome to Paradox City. Hum. Resour. Manag. Int. Dig. 2017, 25, 1-3. [CrossRef]

59. Havermans, L.A.; Hartog, D.N.D.; Keegan, A.; Uhl-Bien, M. Exploring the Role of Leadership in Enabling Contextual Ambidexterity. Hum. Resour. Manag. 2015, 54, s179-s200. [CrossRef]

60. Pelagio Rodriguez, R.; Hechanova, M.; Regina, M. A study of culture dimensions, organizational ambidexterity, and perceived innovation in teams. J. Technol. Manag. Innov. 2014, 9, 21-33. [CrossRef]

61. Schreuders, J.; Legesse, A. Organizational ambidexterity: How small technology firms balance innovation and support. Technol. Innov. Manag. Rev. 2012, 2. [CrossRef]

62. Blindenbach-Driessen, F.; Ende, J.V.D. The Locus of Innovation: The Effect of a Separate Innovation Unit on Exploration, Exploitation, and Ambidexterity in Manufacturing and Service Firms. J. Prod. Innov. Manag. 2014, 31, 1089-1105. [CrossRef]

63. Chen, Y. Dynamic ambidexterity: How innovators manage exploration and exploitation. Bus. Horiz. 2017, 60, 385-394. [CrossRef]

64. Andriopoulos, C.; Lewis, M.W. Exploitation-Exploration Tensions and Organizational Ambidexterity: Managing Paradoxes of Innovation. Organ. Sci. 2009, 20, 696-717. [CrossRef]

65. Van de Ven, A.H.; Poole, M.S. Explaining development and change in organizations. Acad. Manag. Rev. 1995, 20, 510-540. [CrossRef] 
66. Nizam, E.; Ng, A.; Dewandaru, G.; Nagayev, R.; Nkoba, M.A. The impact of social and environmental sustainability on financial performance: A global analysis of the banking sector. J. Multinatl. Financial Manag. 2019, 49, 35-53. [CrossRef] 